Language in Africa 2(2), 2021, 66-82. doi: 10.37892/2686-8946-2021-2-2-66-82

\title{
CONSTRUCTION SCHEMAS IN YORUBA COMPOUNDING: FOCUS ON PERSONAL NAMES
}

\author{
Taiwo O. Ehineni \\ Harvard University \\ taiwo_ehineni@fas.harvard.edu
}

\begin{abstract}
Compounding is a common word-formation process in Yoruba which is instantiated by different compound structures and types. However, in Yoruba personal names, compounds may exhibit significant formal and semantic properties that reflect certain constructional schemas in grammar. Hence, using the framework of construction morphology, this paper examines various schemas in Yoruba compound personal names and the internal features of these schemas. Based on data collected from personal interviews and native speaker intuition, I show that Yoruba personal names are constructions involving complex structural schemas which constitute a form-meaning pair where there are internal features that are not only semantic but syntactic and phonological. Furthermore, the paper reveals that several compound patterns may occur in Yoruba names including $\mathrm{N}-\mathrm{N}, \mathrm{N}-\mathrm{V}, \mathrm{V}-\mathrm{N}, \mathrm{N}-\mathrm{A}$ and $\mathrm{N}-\mathrm{Av}$ and that phonological processes in these schemas may be unique to the name constructions.
\end{abstract}

Key words: construction morphology, compounding, schemas, personal names, Yoruba

\section{Construction morphology: An overview}

Unlike most work in Construction Grammar that focused on phrasal and clausal phenomena, Construction Morphology (CM) specifically provides application of the insights of Construction Grammar to morphological analysis. The framework of CM was extensively developed through a series of works particularly by Booij $(2005 ; 2007$; 
2009; 2010; 2013). This development is informed by previous views by Michaelis and Lambrecht (1996: 216), who claim that "[i]n Construction Grammar, the grammar represents an inventory of formmeaning-function complexes, in which words are distinguished from grammatical constructions only with regard to their internal complexity"; and also by Croft (2001: 17), who observes "...the internal structure of words are also constructions... The only difference between morphological constructions and syntactic ones is that the former are entirely made up of bound morphemes while the latter are largely made up of free morphemes." In the development of the CM framework, Booij emphasizes a continuum view of the relationship between the lexicon and grammar and suggests the use of morphological schemas to express generalizations about form-meaning pairings.

According to Booij (2016), language users can assign internal structure to a word if there is a systematic correlation between its form and meaning. Using the following sets of words such as (a) dancer, fighter, singer, walker and (b) dance, fight, sing, walk, Booij explains that the verbal base is followed by the suffix -er, and a corresponding systematic meaning pattern 'one who Vs', where V stands for the meaning of the verb. Also, the systematic form difference between the words in (a) and those in (b) correlates with a systematic meaning difference - the words in (a) have the additional form component -er, and the additional meaning component 'agent of' (Booij 2016: 424). However, as Booij notes, while the nouns (1a) are considered as deverbal agent nouns and may be assigned an internal structure $[\mathrm{V}-e r] \mathrm{N}$ - there is no reason to assign internal structure to nouns like brother and father that end in the same sequence /or/, because these nouns do not correspond to verbs like broth or fath. Hence, according to Booij, assignment of word structure is based on systematic paradigmatic relationships between sets of words. These relationships may be expressed through the use of morphological schemas. For instance, the form-meaning correlations observed in the English deverbal (agentive) construction can be represented as a constructional schema: $\left.<[\mathrm{x}]_{\mathrm{Vi}} e r\right]_{\mathrm{Nj}} \leftrightarrow$ [Agent of $\left.\mathrm{SEM}_{\mathrm{i}}\right]_{\mathrm{j}}>$ (Booij 2015: 425). 
Basically, the main tenets of Booij's CM are a theory of word grammar and the notion of 'construction'. The theory of word grammar/ structure in $\mathrm{CM}$ is based on the assumption that the word is the minimal linguistic sign, a form-meaning pair. The structure of a word comprises two dimensions - its phonological form and its morpho-syntactic properties. This means that each word links three types of information PHON(ological), SYN(tactic) and SEM(antic) - and morphology or the grammar of words (Booij 2007a) must deal with the systematic relation between all three components (Booij 2010b: 429). Hence, constructions are pairings of form and meaning.

Structurally, the paper is divided into sections. §2 provides a brief background on Yoruba while an overview of Yoruba names in a CM perspective is presented in $\S 3$. In $\S 4$, an in-depth analysis of the constructional patterns in Yoruba name compounds is given, and the findings are summarized in $\S 5$. $\$ 2$ provides a brief background about Yoruba while $\S 3$ and $\S 4$ focus on methodology and analysis.

\section{Yoruba}

Yoruba belongs to the Benue-Congo family of the Niger-Congo language macrofamily, found mostly in South-West, Nigeria. It is the first language of approximately 30 million people, including people in Southwestern Nigeria, parts of Togo, Benin and Sierra Leone, and in other parts of the world such as Brazil, Venezuela, Cuba, Trinidad and Tobago, and Haiti (Schleicher 2008). While the language is referred to as Lucumi in Brazil, and Nago in Cuba, the term "Yoruba" is used for the standard, written form of the language (Dingemanse 2006). The Yoruba language can be classified into three major dialect areas including Northwest, Central, and Southeast; thus there is North-West Yoruba, Central Yoruba and South-East Yoruba (Adetugbo 1982). Based on Adetugbo's dialectological study, North-West Yoruba includes the variety spoken in Ibadan, Lagos, Oyọ, Ọsun and Abeokuta areas of Nigeria. The Central Yoruba variety is spoken in Ekiti, Ifẹ, Akurẹ, Ẹfọn, Ijeșa 
and Igbomina areas of Nigeria, whereas South-East Yoruba is spoken in Ondo, Okitipupa, Owọ, Șagamu and parts of Ijẹbu also in Nigeria. This study focuses on standard Yoruba which is intelligible across all subgroups. While the Yoruba people predominantly occupy the western part of Nigeria, they can also be found in other parts of West Africa and the world at large. The Yoruba linguistic community therefore covers the diasporic people of Yoruba descent who have gone beyond the aboriginal home of the Yorubas in Nigeria and have spread to other West African countries, such as Benin and Togo (Falola \& Childs 2005). Some descendants of the Yoruba people were transported to the New World during the Trans-Atlantic Slavery Trade of the $18^{\text {th }}-19^{\text {th }}$ centuries; most especially to the United States of America, Britain, Brazil, Cuba, Haiti, Trinidad, and Puerto Rico (Adetugbo 1973; Ade-Ajayi 1965). All these Yoruba descendants have been classified as members of the Yoruba Atlantic (Falola \& Childs 2005). Hence, the Yorubas are not specifically a single entity in a place, but essentially, a conglomeration of diverse people bound together by a common history, language, and culture. While they predominantly occupy the western part of Nigeria, they can also be found in other parts of West Africa and the world at large.

Culturally, the Yoruba people are governed by traditional beliefs, customs, traditions and religion. Among the various aspects of Yoruba culture are the naming practices, which is the focus of this paper. Naming is a very important socio-cultural facet of the Yoruba community and is used to identify people's background and affinities. Yoruba names may also perform a few social roles such as to show status, convey experiences, and emotions as well provide instruction to people (Ehineni 2019). Yoruba names constitute a significant repertoire and reservoir of the Yoruba language. They are linguistic forms used by native speakers, and thus, reflects the linguistic system of the language. Hence, a study of personal names is an exploration of relevant aspects or forms of language in a specific linguistic context. 


\section{Methodology}

In this section, we provide a brief description of the method of data collection and analysis. The data, which are personal names, are collected through oral interviews and questionnaires with Yoruba native speakers in Nigeria. The questionnaires were given to the informants to supply different Yoruba personal names that they know of, and their meanings. The subjects included both younger and older speakers of the language for content. However, follow-up interviews were conducted with older people from the Yoruba community since they are culturally regarded to be more knowledgeable about personal names and meanings which helped to elicit the semantics of the names. Also, I used my native speaker intuition in data categorization. The names are discussed structurally where their intrinsic constructional features are specified. In our discussion of these features, we illustrate that linguistic properties pertaining to its form and meaning go hand-in-hand. Although some of their behavior follow from general and specific linguistic principles, they also exhibit an intriguing set of characteristics that cannot be attributed to anything but the schemata in which they appear.

In our analysis, we focus on each name category and the relevant construction schema. Also, various linguistic processes involved in the construction of each name category are discussed. We aim to show, following the $\mathrm{CM}$ framework, that each Yoruba personal name is a specific construction that indexes three properties of information from the lexicon - phonological, syntactic, semantic - and that these properties are unique to the name construction. In other words, Yoruba personal names can be identified and classified based on their distinctive properties. The following sections will identify various compounds in Yoruba personal names and discuss the nature of their constructions.

\section{Analysis of compounding}

Compounding, as Booij (2007: 75) explains, deals with "the combination of lexemes into larger words. In simple cases, compounding consists 
of the combination of two words, in which one word modifies the meaning of the other, the head". Instead of using word-formation rules to analyze compounds, $\mathrm{CM}$ employs constructional schemas which "generalize over a set of existing words with a systematic correspondence between form and meaning" (Booij 2007: 34). As Booij further explains, these abstract schemas specify how new complex words can be created. A schema may therefore be seen as the formal representation of a construction, that is, a particular structural configuration with a specific meaning correlate. For instance, Booij proposes that, the word formation process for compounding in Dutch can be represented as follows: $\left[[a]_{X}[b]_{Y i}\right] Y$ ' $Y_{i}$ with relation $R$ to $X$ ' (Booij 2009).

As Booij explains, the lower case variables $a$ and $b$ in this template stand for arbitrary sound sequences. The use of phonological variables indicates that phonological information does not play a restrictive role in this type of word formation. In terms of meaning, the nature of $\mathrm{R}$ is not specified, but is determined for each individual compound on the basis of the meaning of the compound constituents, and contextual knowledge (Booij 2009: 203). It has also been observed that in many languages certain types of phrases perform similar functions as words (Jackendoff 1997; 2002; Booij 2002). This leads to the development of compound-like phrases such as A-N compounds (adjective noun compounds) (i.e black box, cold war, etc.), which may also be considered lexical even though they are internally phrasal (Giegerich 2005; Booij 2010). In other words, black box may be considered as a lexical item for a concept but has two words internally. ${ }^{1}$

The next section will specifically explore the issue of compounding in Yoruba names with a view to exploring the extent to which the framework of construction morphology can account for various compound types in the names. First, while Booij's studies on CM have

${ }^{1}$ I understand that there is a difference between black box (a box which is black in color) and a blackbox (which does not have to be black). Both have "two words" internally. Hence, it is possible to distinguish between both forms in conceptual terms. 
identified a number of compound types in Dutch (including N-N, A-N, V-N) some other compound types may occur in Yoruba names. Second, and more significantly, is the fact that these compound types may reflect other patterns different from regular word formation patterns in Yoruba.

\subsection{Compounding in Yoruba personal names}

Compounding is a major word formation process in Yoruba (Akinlabi 2001: 839). However, it often involves noun + noun combinations and verb + noun combinations, such as the following words in (1)-(8) which are examples cited from Adewole (1995: 46).
(1) eyẹlé - eye ilé 'pigeon'
(2) omobinrin - omo obinrin 'girl' child female
(3) otíkà - otí okà 'Guinea corn wine' wine Guinea.corn
(4) ewyébẹ - ewé obẹ 'vegetable leaf' leaf soup
(5) wálé - wá ilé 'come home' come home
(6) wayò $\quad-$ wo ayò 'see joy' see joy
(7) sobè - se obẹ 'cook the stew' make stew

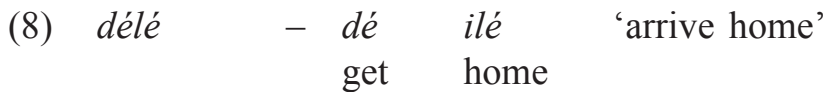

In the above examples, the words in (1)-(4) involve noun-noun $(\mathrm{N}-\mathrm{N})$ combinations, while (5)-(8) reveal noun-verb $(\mathrm{N}-\mathrm{V})$ combinations. The example, ewébè (4), unlike other examples, shows that the head occurs in a final position. However, in names, it is possible for other patterns to occur. Specifically, uncommon patterns such as noun + verb, noun + adverb, noun + adjective are possible as shown in (9)-(12). 


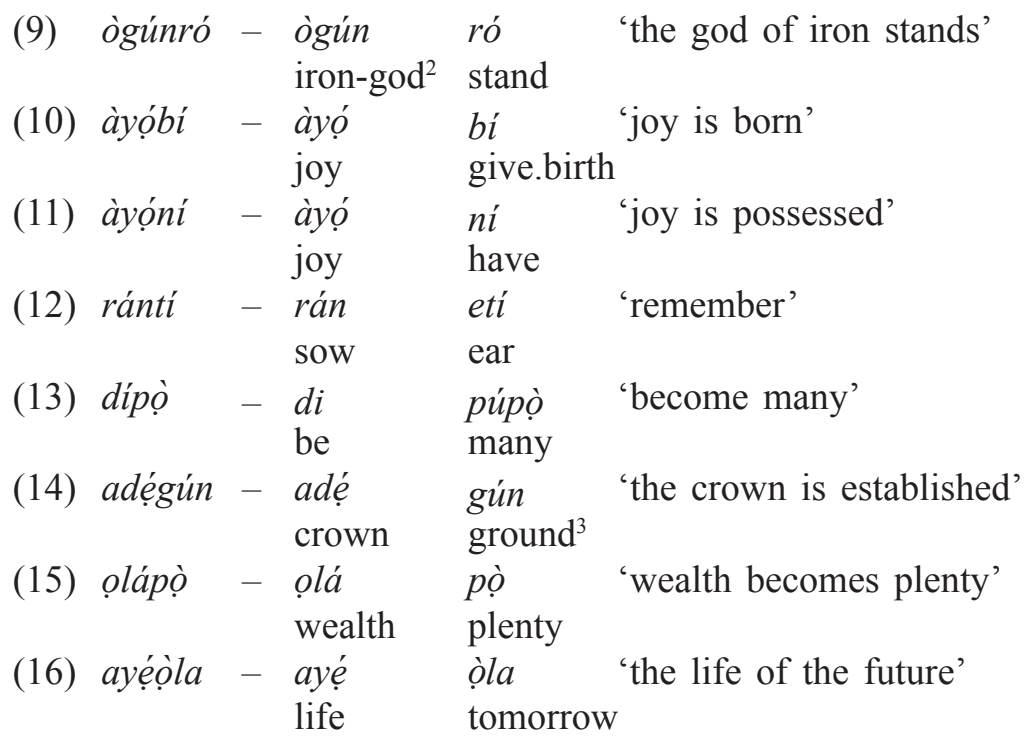

It should be noted that the adjectives in (14) and (15) are deverbal adjectives and may also occur with nouns in names. The personal names in (9)-(13) and (16) show that nouns can also combine with verbs and adverbs to form names. Essentially, these names do not only reflect common N-N combinations in nominal constructions in Yoruba; they may only occur in names. In other words, the patterns used in lexically deriving the names reveal different ways of word formation

${ }^{2}$ Ogún is the god of iron among the Yoruba orishas. These include Sango god of thunder, Ifa god of wisdom, Osun goddess of fertility, Oya goddess of beauty, Yemoja mermaid-goddess among others. It is common for Yoruba personal names to reflect religious affiliations to any of the different orishas.

${ }^{3}$ The verb gún is used in different ways and may have different conotations. While the word gún literally means 'to grind' or 'to stab', it is also used as gún lè which means 'to be settled or established in a place'. Also, when the syntactic role of gún, either transitively or intransitively, may affect its meaning. Here, it is used intransitively and takes the meaning of settlement and establishment. If it is being used as a transitive verb, it would mean the crown hurts an object or a patient. 
in Yoruba. However, the personal names in (14)-(15) show a combinatorial possibility of nouns and adjectivals.

Based on the CM framework, construction schemas for various types of possible compound forms in Yoruba are presented in (17)-(21) below.

(17) N-V compound names: $\left[[\mathrm{N}]_{\mathrm{i}}[\mathrm{V}]_{\mathrm{j}}\right]_{\mathrm{Ni}}$

(18) N-Adj compound names: $\left[[\mathrm{N}]_{\mathrm{i}}[\mathrm{A}]_{\mathrm{j}}\right]_{\mathrm{Ni}}$

(19) N-Av compound names: $\left[[\mathrm{N}]_{\mathrm{i}}[\mathrm{Av}]_{\mathrm{j}}\right]_{\mathrm{Ni}}$

(20) N-N compound names: $\left[[\mathrm{N}]_{\mathrm{i}}[\mathrm{N}]_{\mathrm{j}}\right]_{\mathrm{Ni}}$

(21) V-N compound names: $\left[[\mathrm{V}]_{\mathrm{i}}[\mathrm{N}]_{\mathrm{j}}\right]_{\mathrm{Nj}}$

While several schemas are possible in Yoruba compound names, schemas such as $\left[[\mathrm{N}]_{\mathrm{i}}[\mathrm{N}]_{\mathrm{j}}\right]_{\mathrm{Ni}}$ for N-N compound names and $\left[[\mathrm{V}]_{\mathrm{i}}[\mathrm{N}]_{\mathrm{j}}\right]_{\mathrm{Nj}}$ for $\mathrm{V}-\mathrm{N}$ compound names are more common in Yoruba regular nominal constructions. A more elaborate illustration of these various schemas with relevant examples is given in the Table 1.

Table 1

Schemas in Yoruba personal names

\begin{tabular}{|c|c|c|c|c|}
\hline$\left[[\mathbf{N}]_{\mathrm{i}}[\mathbf{N}]_{\mathrm{j}}\right]_{\mathrm{Ni}}$ & {$\left[[\mathbf{N}]_{\mathrm{i}}[\mathbf{V}]_{\mathrm{j}}\right]_{\mathrm{Ni}}$} & {$\left[[\mathbf{V}]_{\mathrm{i}}[\mathbf{N}]_{\mathrm{j}}\right]_{\mathrm{Ni}}$} & {$\left[[\mathbf{N}]_{\mathrm{i}}[\mathbf{A}]_{\mathrm{j}}\right]_{\mathrm{Ni}}$} & {$\left[[\mathbf{N}]_{\mathrm{i}}[\mathbf{A v}]_{\mathrm{j}}\right]_{\mathrm{Ni}}$} \\
\hline $\begin{array}{l}\text { adé-ògo } \\
\text { crown-glory }\end{array}$ & $\begin{array}{l}a y \grave{o}-b i \\
\text { joy-born }\end{array}$ & $\begin{array}{l}\text { gba-adé } \\
\text { take-crown }\end{array}$ & $\begin{array}{l}\text { olá-pò } \\
\text { wealth-plenty }\end{array}$ & $\begin{array}{l}\text { ayééòla } \\
\text { life-tomorrow }\end{array}$ \\
\hline $\begin{array}{l}\text { adé-agbo } \\
\text { crown-crowd }\end{array}$ & $\begin{array}{l}\text { adé-yí } \\
\text { crown-to turn }\end{array}$ & $\begin{array}{l}\text { wo-ilé } \\
\text { enter-house }\end{array}$ & $\begin{array}{l}\text { ayé-ké } \\
\text { world-cherish }\end{array}$ & $\begin{array}{l}\text { àyò-ká } \\
\text { joy-about }\end{array}$ \\
\hline $\begin{array}{l}\text { ibú-olá } \\
\text { ocean-wealth }\end{array}$ & $\begin{array}{l}\text { ogún-ró } \\
\text { irongod-to stand }\end{array}$ & $\begin{array}{l}k \grave{o}-\text { ìyà } \\
\text { reject-poverty }\end{array}$ & $\begin{array}{l}\text { adé-nlá } \\
\text { crown-big }\end{array}$ & $\begin{array}{l}\text { igbé-òla } \\
\text { living-tomorrow }\end{array}$ \\
\hline $\begin{array}{l}\text { iyì-olá } \\
\text { honor-wealth }\end{array}$ & $\begin{array}{l}\text { ìyá-bò } \\
\text { mother-to return }\end{array}$ & $\begin{array}{l}\text { dì-ìrán } \\
\text { become-vision }\end{array}$ & $\begin{array}{l}\text { ibi-dún } \\
\text { birth-sweet }\end{array}$ & $\begin{array}{l}\text { àmò-ká } \\
\text { knowledge-about }\end{array}$ \\
\hline
\end{tabular}


First, all the compound structures specified above for Yoruba personal names have nouns which suggests that there are nominals. The meaning of each construction is a product of the holistic properties of that construction. This therefore confirms the view that "systematic properties of compounds need not be derived from the head, but can be seen as holistic properties of the compound construction" (Booij 2012: 345). Thus, each construction (each name) has a unique meaning based on the internal lexical properties of each construction.

\subsection{Phonological processes in compound schemas}

A significant aspect of construction schemas in CM is that they reflect a variety of properties in a that is based on "a pairing of three types of information ... labelled as PHON (phonological), SYN (syntactic), and SEM (semantics)" (Booij 2010: 429). Hence, based on the PHON category in construction schemas, there may be phonological processes unique to constructions reflected in their schemas. These phonological properties may reflect common phonological processes or show unique ones. In Yoruba, vowel elision has been observed to occur in Yoruba in intervocalic contexts (see Akinlabi \& Oyebade 1987; Pulleyblank 1988; Orie \& Pulleyblank 2002), however in compound personal names shown in (12) and (13) vowel elision occurs. These examples are repeated in (22) and (23).

$\begin{aligned} \text { (22) ránti }- & \text { rán etí 'remember' } \\ & \text { sow ear } \\ \text { (23) dípọ }- & d i \quad \text { púpò 'become many' } \\ & \text { be many }\end{aligned}$

The personal names above follow the vowel deletion rule over a morpheme boundary since the vowels /e/ is deleted over the morpheme boundary in (22). However, in (23), a syllable is deleted instead of a vowel. Hence, in compound names, apart from vowel deletion in morpheme boundary (Orie \& Pulleyblank 2002), a syllable may also be deleted. Also, this is a unique type of deletion because 
it is not an intervocalic context. This form of vowel deletion is a constructional phonological property of personal names in Yoruba. In fact, vowel deletion may occur word initially as shown in (24)-(25).

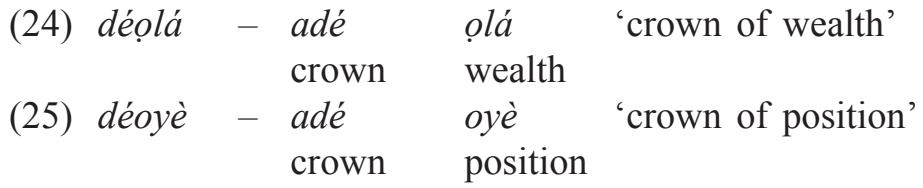

Here, the deletion is not motivated by an intervocalic context since it occurs at the beginning of a word not between two vowels. Also, note that no deletion occurs in the intervocalic situation [dé-ọlá] in (24) and [dé-oyè] in (25) as would be expected as part of a vowel hiatus resolution strategies in Yoruba (Orie \& Pulleyblank 2002) where vowel deletion disccused to occur to prevent vowel co-occurence over a morpheme boundary. Here, vowel deletion occurs word initially (where it is unusal) and does not intervocalically (where it is more common).

Another important phonological feature is consonant deletion, which may be seen in names in (26)-(27).

(26) báatúndé - bàbá tún dé 'The father has come again.' father again come-PRF

(27) báájídé - bàbá jí dét 'The father has woken.' father wake come-PRF

${ }^{4}$ The morpheme dé is a verbal element that occurs in serial constructions common in Yoruba. Serial constructions are constructions where two or more verbs are strung together as a verb phrase. These constructions may be a sequence of verbs where the verbs occur consecutively with nothing intervening as in (i).

(i) Mo sùn lọ

$1 \mathrm{SG}$ slept go

'I slept off' 
Here, the consonant $/ \mathrm{b} /$ deletes in an intervocalic context [a $-\mathrm{a}$ ] especially between two similar vowels. It is important to also note that this is not a morpheme boundary situation since bàbá is is not formed through the combination of $b \grave{a}$ and $b a ́$ where each is a separate morpheme on its own. The morpheme bàbá 'father' is a single morpheme on its own. Hence, construction schemas of personal names may show unique phonological processes to typify the constructional properties of these personal names

\subsection{Headedness in compounding}

A major area that has been debated widely in compounding is the issue of headedness. On this area, Booij (2009: 210) comments that "since Williams (1981) the importance of the notion 'head' for the analysis of morphological constructs has received new recognition and attention. It is clear that Williams' Right Hand Rule cannot be a rule in the sense of a universal since many languages have left-headed compounds". In other words, the position of the head is variable across languages. Similarly, in Yoruba names, the head in nominal N-N compounds may be left or right positioned. Thus, as illustrated above in table 1, compounds such as N-N, N-V, N-Adj and N-Adv may be considered left-headed, since the noun functions as head of the construction. For instance, in example adéògo, illustrated in (28).

(28) left headedness in Yoruba N-N name compounds

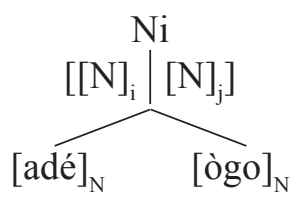

Or with the object of one of the verbs, coming in between the serialized verbs as shown in (ii).

(ii) Mo gbé owó wá $1 \mathrm{sg}$ carry money come

'I brought money.' 
The morpheme adé provides a major semantic input in the interpretation of the entire name. Note that it is the morpheme adé 'crown' that typifies the entire name adéogo as a kingship name. Hence, adéogo 'crown-glory' is a type of crown. The same left-head position occurs in other forms such as $\mathrm{N}-\mathrm{V}, \mathrm{N}-\mathrm{A}$ and $\mathrm{N}-\mathrm{Av}$ where the noun is the head of the nominal compound. However, V-N name compounds may be right-headed as shown in (29) below.

(29) right headedness in Yoruba name V-N compounds

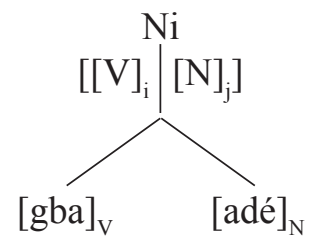

The compound name gba-adé 'take-crown' is another form of kingship name, but has a V-N compound structure. Crucially, the noun adé 'crown' identifies this construction as a kingship name. Essentially, as shown in Yoruba names, V-N name compounds are right-headed and this is not uncoonected with the issue of verb transitivity, where the verb requires a noun object. This creates a VP structure where the $\mathrm{V}$ is the head of the phrase. However, in N-N name compounds, the position of the head may vary. Consider the name given in (30).

(30) left headedness in Yoruba N-N name compounds

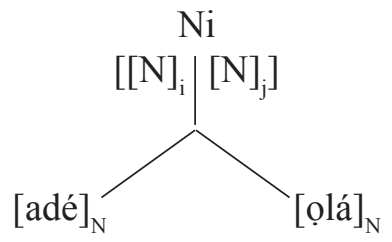

The name adé-olá means 'crown-wealth' is a special kingship name with a N-N structure. Like other previous kingship names, the noun adé 'crown' provides the kingship orientation that distinguishes this name from other general names. Here, there are two nouns adé is 
the head and olá is the modifier since it depicts the typology of the crown. However, there could be other N-N name structures where the head category adé, which categorizes the entire name as kingship name, changes position. This positional change is shown in (31).

(31) left-right headedness in Yoruba N-N name compounds

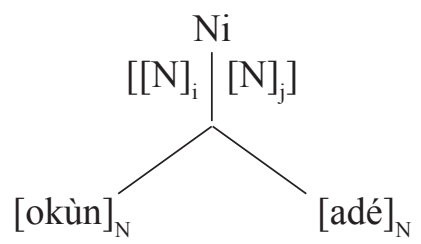

In okùn-adé 'rope-crown' the kingship lexical identifier is leftpositioned unlike in (30). This is a unique $\mathrm{N}-\mathrm{N}$ structure. A reviewer suggested that this seems to relate to left-headedness, rather than rightheadeness arguing that okùn is the head, while Adé is the limiting modifier indicating possession citing examples such as ilé Ade 'Ade's house (lit. house Ade)', ilé mi 'my house (lit. house my)'. This is true in the context of Yoruba possessive constructions where the head precedes the modifier. However, in names, there may also be two types of heads - syntactic and semantic. The syntactic head may be positionally determined since it is based on the position within the structure as determined by grammar. However, the semantic head may not necessarily be, since it is determined by meaning. This is especially manifest in names such as okùnadé where the noun adé 'crown' provides the kingship categorization of the name and separates it from the multitude of other names. Hence, adé in the okùnadé name structure would be the semantic head while okún may be the syntactic head based on its positionality in the phrase. Essentially, the (semantic) head is variable in Yoruba compound names and significantly identifies a name category from other name categories in terms of meaning. More importantly, through the various compound structures that we have explored in this section, we suggest that Yoruba names may exhibit other combinations that are not common in Yoruba compound nominals. 


\section{Conclusion}

Following the CM framework, the paper shows that Yoruba personal names exhibit various construction patterns, these patterns include N-N, $\mathrm{N}-\mathrm{V}, \mathrm{V}-\mathrm{N}, \mathrm{N}-\mathrm{Adj}$ and N-Adv. The position of the head is however variable. That is, in Yoruba names, the head in nominal compounds may be left or right positioned. Specifically, compounds such as N-N, $\mathrm{N}-\mathrm{V}, \mathrm{N}-\mathrm{Adj}$ and $\mathrm{N}-\mathrm{Adv}$ are considered left-headed since the noun functions as head of the construction, while V-N compounds are seen as right-headed where the nominal head occupies in a rightward position. However, in N-N structures, the head may be leftward or rightward as illustrated in kingship names okùn-adé 'rope-crown' (rightward) and adé-ògo 'crown-glory'. Here, the noun adé 'crown' is seen as the head since it provides the kingship orientation that principally distinguishes this name from other category of names. On the contrary, if we assume okùn to be the head in okùn-adé 'ropecrown', this would disqualify the construction as a unique kingship name headed by adé, just like the other examples discussed. This is also the case for $\mathrm{V}-\mathrm{N}$ and $\mathrm{N}-\mathrm{V}$ nominal compounds, where the $\mathrm{N}$ is seen as the head of the nominal construction. Hence, V-N is rightheaded while $\mathrm{N}-\mathrm{V}$ is leftheaded. This distinction is illustrated by kingship names such as gbá-adé 'take-crown' and adé-agbo 'crown-crowd' where the adé 'crown' serves as the construction head, typifying these constructions as specifically kingship names. Arguably, as kingship names demonstrate, headedness is variable in Yoruba compounds. ${ }^{5}$

Finally, by employing a constructionist approach in our analysis, it is advanced that the framework of construction morphology may be applied to the study of Yoruba personal names. Through this framework, we show that each Yoruba name is a unique construction involving not

${ }^{5}$ Again it is necessary to distinguish between a semantic head and a syntactic head, where in the V-N compound gba-adé 'take-crown', the V may be the syntactic head as a verbal construction, while the $\mathrm{N}$ is seen as the semantic head as a kingship nominal construction. However, in the $\mathrm{N}-\mathrm{V}$ compound adé-ògo 'crown-glory', the $\mathrm{N}$ is the semantic head as well as the syntactic head. 
only structural features but also phonological properties. These phonological properties may be unique to the schemas of personal names construction in Yoruba rather than being regular across other word formation contexts. It is therefore shown that Yoruba personal names may reflect compound schemas and these schemas are typified by unique properties and linguistic processes.

\section{Abbreviations}

$\mathrm{CM}$ - construction morphology $\quad$ PRF - perfective (aspect)

$\mathrm{SYN}$ - syntactic $1 \mathrm{SG}-1 \mathrm{st}$ person singular (pronoun)

PHON - phonological

$\mathrm{N}-$ noun

SEM - semantic

$\mathrm{V}-\mathrm{verb}$

$\mathrm{A}$ - adjective

$\mathrm{Av}-\mathrm{adverb}$

\section{References}

Ade-Ajayi, Jacob. 1965. Christian missions in Nigeria: The making of a new elite. London: Longman

Adetugbo, Abiodun. 1982. Towards a Yoruba dialectology. In Afolayan, Adebisi. (ed.), Yoruba language and literature, 207-224. Ife - Ibadan: University Press.

Adetugbọ Abiodun. 1973. The Yorùbá language in Yorùbá History in Sources of Yorùbá History. Ibadan: University Press Limited.

Adewole, Samuel. 1995. Word formation processes in Yoruba. Los Angeles: University of California. (Ph.D. dissertation.)

Akinlabi, Akinbiyi. 2001. Yoruba. In Garry, Jane \& Rubino, Carl (eds.), Facts about the World's languages: An encyclopedia of the World's languages: past and present, 836-841. New York - Dublin: HW Wilson. Booij, Geert. 2002. Constructional idioms, morphology, and the Dutch lexicon. Journal of Germanic Linguistics 14(4). 301-329.

Booij, Geert. 2009. Compounding and construction morphology. In Lieber, Rochelle \& Štekauer, Pavol(eds.), The Oxford handbook of compounding, 201-216. Oxford: Oxford University Press.

Booij, Geert. 2010. Construction morphology. Oxford: Oxford University Press. Booij, Geert. 2013. Morphology in CxG. In Hoffmann, Thomas \& Trousdale, Graeme (eds.), The Oxford handbook of construction grammar, 255273. Oxford: Oxford University Press. 
Booij, Geert. 2016. Construction morphology. In Hippisley, Andrew \& Stump, Gregory (eds.), The Cambridge handbook of morphology, 424-448. Cambridge: Cambridge University Press.

Booij, Geert. 2002. The morphology of Dutch. Oxford: Oxford University Press. Booij, Geert. 2005. Compounding and derivation: Evidence for construction morphology. In Dressler, Wolfgang U. \& Kastovsky, Dieter \& Pfeiffer, Oskar E. \& Rainer, Franz (eds.), Morphology and its demarcations, 109-132. Amsterdam: John Benjamins. (Selected papers from the $11^{\text {th }}$ Morphology meeting.)

Booij, Geert. 2007. The grammar of words: An introduction to linguistic morphology. Oxford: Oxford University Press.

Croft, William. 2001. Radical construction grammar: Syntactic theory in typological perspective. Oxford: Oxford University Press.

Dingemanse, Mark. 2006. The body in Yoruba: A linguistic study. Leiden: Leiden University. (M.A. Thesis)

Ehineni, Taiwo. 2019. The ethnopragmatics of Yoruba personal names: Language in the context of culture. Studies in African Languages and Cultures 53, 69-90

Falola, Toyin and Childs, Matt. 2005. The Yoruba diaspora in the Atlantic world. Bloomington: Indiana University Press

Giegerich, Heinz J. 2015. Lexical structures: compounding and the modules of grammar. Edinburgh: Edinburgh University Press.

Ìkotún, Reuben. 2010. The social use of Yorùbá personal names. Names 58(3). 169-186.

Ìkotún, Reuben. 2014. Wrong forms of some Yorùbá personal names: Some phonological and sociolinguistic implications. Linguistik Online 68. 43-56.

Jackendoff, Ray. 1997. The architecture of the language faculty. Cambridge, MA: MIT Press.

Jackendoff, Ray 2002. Foundations of language: brain, meaning, grammar, evolution. Oxford: Oxford University Press.

Orie, Olanike \& Pulleyblank, Douglas. 2002. Yoruba vowel elision: minimality effects. Natural Language \& Linguistic Theory 20. 101-156.

Schleicher, Antonia Yetunde. 2008. Colloquial Yoruba: The complete course for beginners. London: Routledge.

Taiwo, Oye. 2009. Headeness and the structure of somplex Yoruba words. Taiwan Journal of Linguistics 7(1). 27-52.

Received 24.03.2021. Received in revised form 28.05.2021. Accepted 02.06.2021 